\title{
Mathematica: Teaching Learning Process at Secondary School Level in Punjab
}

\author{
${ }^{a}$ Najam ul Kashif, ${ }^{\mathrm{b}}$ Musarrat Jahan, ${ }^{\mathrm{c}}$ Samina Ashraf, ${ }^{\mathrm{d}}$ Muhammad Latif Javed \\ ${ }^{a}$ Assistant Professor, Department of Education, The Islamia University of Bahawalpur, Pakistan \\ Email: drnajam.ulkashif@iub.edu.pk \\ ${ }^{\mathrm{b}}$ Assistant Professor, Department of Special Education, The Islamia University of Bahawalpur, Pakistan \\ Email: musarrat.jahan@iub.edu.pk \\ ${ }^{c}$ Assistant professor, Institute of Special Education, University of the Punjab, Lahore, Pakistan \\ Email: samina.dse@pu.edu.pk \\ d Assistant Professor, Department of Education, The Islamia University of Bahawalpur, Bahawalnagar Campus, \\ Pakistan \\ Email: latif.javed@iub.edu.pk
}

\begin{tabular}{l}
\hline ARTICLE DETAILS \\
\hline History: \\
Accepted 29 October 2021 \\
Available Online December 2021 \\
\hline Keywords: \\
Technology, Knowledge, \\
Mathematics, Secondary School
\end{tabular}

JEL Classification:

O14, $D 83, P_{3} 6$

DOI: $10.47067 /$ real.v4i4.196

\begin{abstract}
Technology becomes an integral part of academia. Computer or technology is rooted out from Mathematics. When it is said that 21st century is the century of technology, then how the field of education is remained away from technology. Modern science labs are technology oriented and in such a way the subject of Mathematics is also shifted on technology. Mathematics is not an integral part of daily routine life as well as playing a key role in the progress of science and technology. In the teaching learning process, technology-based teaching is the modern mode of teaching. Keeping in mind the same scenario, current study was conducted to highlight the concept of Mathematica (Mathematics and Information Technology) in the teaching learning process at secondary school level in Punjab province. Study aimed at to observe the technology role on the mathematics' teaching at secondary school level. The study was quantitative by nature and descriptive approach was adopted. Self-developed questionnaire was applied as a research tool to get the data from the target sample through survey technique. Total targeted sample was 60 teachers who are teaching Mathematics at secondary school level and their 200 students. Findings of the study revealed that technology usage in the teaching learning process of mathematics enhance the understanding of the mathematical concepts many times.
\end{abstract}

(C) 2021 The authors. Published by SPCRD Global Publishing. This is an open access article under the Creative Commons AttributionNonCommercial 4.0

Corresponding author's email address: drnajam.ulkashif@iub.edu.pk

\section{Introduction}

With respect to teaching mathematics, it is a subject that flows on logical reasoning to reach the conclusion. So, it builds habits of learners to think logical reasoning that according to Aristotle (Politics- 
VII) is a major aim of education. In the same way if we sum up three main considerations of education by great scholars of education (Rousseau, 1880; Einstien, 1950; \& Maslow, 1954) for sending a child to school are;

- To acquire knowledge and skill: Practical or Utilitarian value.

- To develop intellectual habits and power: disciplinary value

- To develop desirable attitude and ideals: the cultural values.

With respect to knowledge and skills that are of practical value, and practical implementation of Mathematics in daily routine life is shining like a moon. Everybody irrespective of their social status or profession one belongs, makes use of mathematical knowledge in daily life. For example, a labourer calculates his/her wages, and every person calculates while purchasing from market and so on. No human can deny the usage of simple arithmetic operations i.e., plus, minus, division and multiplication in their everyday life and in every profession.

With respect to creation of intellectual thinking as mathematical calculation works in logical orders that help to create disciplinary habits in a learner. By learning mathematics, a learner builds habits of logical thinking which are based on different concepts and theories. As a result, man becomes more critical and logical thinker. With respect to cultural values, education, and to understand the history and development of man on this universe, mathematical figures play a central role (Abramovich, Arcadii, \& Milligan, 2019). To show the intensity of any plague, to measure the eras of human development, to check the progress of any individual or group or community or nation, the figures and diagrams of mathematics are there to help us. So, in present world it seems impossible to live without having a basic knowledge of mathematics. If we want to travel, we need maps and distance, to measure the distances, to reach on the destinations, usage of different geometric tools is common in our life. So, it can be said that human life without maths is unimaginable. It is knowledge and skills that make a person to practice education in ones' practical life. Truly speaking the ignorance of mathematics in the masses is a formidable obstacle on the way to progress. In the absence of these fixations, life in the present-day society will be full of confusion and chaos (National Research Council, 2000).

But with respect to teaching there are different points of view about necessity of different types of reforms in its teaching because it is taken as a dull subject. It is the joint responsibility of all concerned to bring about necessary improvements and changes in teaching methods of this subject. This subject must be popularized at any cost (Sindhu, 1988). So, for this purpose use of technology in class can be helpful and to see this, this study was conducted.

The teachers cling to traditional methods because these offer the path of least resistance. Logical reasoning development among the students by using different thinking approaches like creative thinking, critical thinking is in the part of mathematics. And those students who remain unable to move with logical reasoning approach are considered as rote learners and their level of understand is not considered up to a mark. On the other hand when it is said that it is an age of automation. As human has invented machines for every field of life which has made his/her works easy, quick, and reliable and for teaching purpose computers are there to help a mathematician (Yeo, 2008). This has its origin in man's attempts to devise ways and means to facilitate human beings. It can perform several operations simultaneously and in short times as well as errors free. It serves as a mediation tool or agent facilitating learning process (Oldknow, \& Taylor, 2002). 
So, the use of technology in the subject of mathematics for teaching purpose offer the learners different skills which are necessary in our daily life like confidence building, mapping the mind with logical reasoning, developing creative and critical thinking approaches, and apply the different mathematical abstract theories in their practical life (Cantürk-Günhan \& Bukova-Güzel, 2010). It creates motivation for learning and shift towards more pupil-centered learning environments (Smeets, 2005). The use of mathematical software and websites are useful in developing different empirical approaches and skills among students. Perfection comes through practice, and this is very true in doing mathematics with the help of technology. By adopting drill and practice approach for mathematics with help of technology, students not only become expert of mathematics but also of technology. For example, with the help of software for example MATHCAD, MATHMANIA, SPSS, etc complex equations can be calculated within short period of time that if calculated manually take a long time even hours to complete the procedure. Computer when used appropriately, it makes the students to work smart as the modern era is not only of hard working but also of smart working (Regina \& Mistretta, 2005). In the same pattern, if teachers get trainings of technology usage in the teaching, it also help them to be smart workers and instructional technology is ready to speed up their working and boost up their teaching approaches (Goose \& Bennison, 2007).

Computers perform about all functions on behalf of mathematical formulas so, to understand computers' functions; knowledge of mathematics is necessary. In the same way, computer helps in mathematical calculations. It means that both kind of knowledge help each other. It also provides some insight into what may be going on in computer while solving a problem. Problem solving in mathematics can be explained as "thinking and working mathematically" but the converse is not true. Problem solving in mathematics is an intricate process which calls for a problem solver to be engaged in a mathematical task to organize and deal with domain-specific and domain-general pieces of knowledge (Hartsell, Herron, Fang, \& Rathod, 2009). Its' other function is to motivate students to learn by solving complex equations in short time that may take sometimes hours and students feel boredom because for meaningful of learning tasks (Grabe, \& Grabe, 2000). The other role of IT (Information technology) in schools is an enabler in learning (Grabe, \& Grabe, 2000).

The use of computer technology in education posed new teaching challenges and many educators are expected to be able to use computer for instruction and learning purposes. According to Neiss cited by (Kumar, 1993) computer competencies for teachers should mainly involve the ability to use computers to enhance curriculum and instruction and be an inevitable part of curriculum. In manually performing, computation process goes longer, first to read and understand, know which strategy to use, which formula is to apply, putting values in it, certain types of calculations, summing up conclusions then checking it to reach valid solution. But by using computer, a person has only to know which software and program to use and saves the time and energy (O'Neil, Anne-Marie, Clark, \& Openshaw, 2004).

The use of internet is now a day a common facility in all disciplines due to creating learning environment by providing variety of learning material. It enables learners to master content and extends their investigations to become more self-directed and assumes greater control over their own learning and these features are fundamental features that e-learners are required to have. According to Kiliç-Çakmak (2010), by using internet a learner can access required information effectively and efficiently as well as up to date. So, teachers by using ICT (information and communication technology) in classroom either real or virtual or both must be equipped with resources and skills to teach effectively the necessary subject matter content while incorporating technology concepts and skills (UNESCO, 2018). 


\section{Study's Aim}

Technology becomes an integral part of academia. Computer or technology is rooted out from Mathematics. When it is said that $21^{\text {st }}$ century is the century of technology, then how the field of education is remained away from technology. Modern science labs are technology oriented and in such a way the subject of Mathematics is also shifted on technology. Mathematics is not an integral part of daily routine life as well as playing a key role in the progress of science and technology. In the teaching learning process, technology-based teaching is the modern mode of teaching. Keeping in mind the same scenario, current study was conducted to highlight the concept of Mathematica (Mathematics and Information Technology) in the teaching learning process at secondary school level in Punjab province. Study aimed at to observe the technology role on the mathematics' teaching at secondary school level.

\section{Research Design}

In this study, male and female students of class $10^{\text {th }}$ from government and private schools as well as their teachers from the school of Multan District, Pakistan were taken as population of this study. Total targeted sample was accessed by adopting simple random sampling technique and as a result, 60 teachers who are teaching Mathematics at secondary school level and their 200 students. The detail of study's sample is as under:

- Five boys' government and private high schools and five girls' government and private high schools of Multan city were selected.

- Sampling proportion of 100 government and 100 private school students as well as 30 government and 30 private secondary school teachers who are teaching Mathematics in their schools.

Two self-structured survey questionnaires based on five-point Likert scales were developed, one for students and the second for teachers teaching mathematics at secondary level to collect the required information. Questionnaires were got validated by senior professors of the department of education Bahauddin Zikriya University, Multan, Pakistan. The experts suggested minor changes in the statements that were performed. The questionnaires were also got filled by respondents for pilot study. So, a final version of questionnaires was finalized and launched. After getting the permission from the head of the institutions and under the supervision of concerned class teacher, the researcher administrated the questionnaire in each target school. There was no problem of discipline getting opinions of the students on the questionnaire. The researcher himself explained to the students and the teachers the purpose of the questionnaire. To reach certain conclusion, simple percentage with mean score and standard deviation of respondents' responses of sample that agreed or disagreed to the statements were calculated and presented in tables.

\section{Findings}

After collecting data simple percentage of agree and disagree responses was calculated. In findings table should be read as A as Agree; DA as Disagree (all values are given in percentages); Mean as Arithmetic Mean Score and S.D. as Standard Deviation 
TABLE-1

\begin{tabular}{|l|l|l|l|l|l|}
\hline & \multicolumn{1}{|c|}{ Item } & \multicolumn{1}{|c|}{ A } & \multicolumn{1}{|c|}{ DA } & Mean & \multicolumn{1}{c|}{ S.D. } \\
\hline Teachers & \multirow{2}{*}{ Link Between Math and ICT } & 95.5 & 4.5 & 4.95 & 0.67 \\
\hline Students & & 93.7 & 6.3 & 4.91 & 0.63 \\
\hline Teachers & \multirow{2}{*}{ ICT is a valuable source for Mathematics Teachers } & 98.1 & 1.9 & 4.92 & 0.49 \\
\hline Students & & 95.5 & 4.5 & 4.80 & 0.42 \\
\hline Teachers & \multirow{2}{*}{ Internet usage for the Mathematics teaching promotion } & 79.2 & 20.8 & 4.65 & 0.58 \\
\hline Students & & 82.2 & 17.8 & 4.85 & 0.36 \\
\hline Teachers & \multirow{2}{*}{ Mathematics teachers' ability to use the technology } & 75.5 & 24.5 & 3.66 & 1.38 \\
\hline Students & & 89.1 & 10.9 & 4.62 & 0.49 \\
\hline Teachers & \multirow{2}{*}{ Learning mathematics through computer } & 93.7 & 6.3 & 4.78 & 0.42 \\
\hline Students & & 64.4 & 35.6 & 3.29 & 1.45 \\
\hline Teachers & \multirow{2}{*}{ Updated knowledge through ICT } & 87.7 & 12.3 & 4.70 & 0.46 \\
\hline Students & & 76.4 & 23.6 & 4.32 & 0.98 \\
\hline Teachers & \multirow{2}{*}{ ICT reduces the manual work } & 98.2 & 1.8 & 4.92 & 0.49 \\
\hline Students & & 82.2 & 17.8 & 4.85 & 0.39 \\
\hline Teachers & \multirow{2}{*}{ Teachers visit the relevant web sources } & 83.7 & 16.3 & 4.78 & 0.42 \\
\hline Students & & 76.3 & 23.7 & 4.19 & 0.83 \\
\hline Teachers & \multirow{2}{*}{ Mathematics with modern technology } & 91.9 & 8.1 & 4.92 & 0.45 \\
\hline Students & & 81.1 & 18.9 & 4.79 & 0.96 \\
\hline Teachers & \multirow{2}{*}{ Math becomes by using technology } & 84.1 & 15.9 & 4.82 & 0.38 \\
\hline Students & & 79.2 & 20.8 & 4.21 & 1.08 \\
\hline Teachers & \multirow{2}{*}{ Technology is getting attention of students } & 78.2 & 11.8 & 4.07 & 1.12 \\
\hline Students & & 75.5 & 24.5 & 4.30 & 1.01 \\
\hline Teachers & \multirow{2}{*}{ ICT is a source of entertainment } & 38.6 & 71.4 & 1.45 & 0.59 \\
\hline Students & & 40.8 & 59.2 & 1.40 & 0.982 \\
\hline
\end{tabular}

The results of the first statement shows that $95 \%$ of the teachers teaching mathematics are in the favour of agreed option. While about $94 \%$ student respondents replied in agree too. So, it can be said that majority of the students and teachers are agree that ICT and mathematics are interlinked. The results of the second statement shows that $100 \%$ of the teachers replied in agree option and about $96 \%$ students' respondent replied in agree. Majority of the teachers are in favour that ICT is a valuable source of information for the teachers of mathematics. In the same pattern, the results of the third statement shows that $79 \%$ of the teachers responded in agree and $82 \%$ students are in the favour of agreed option. So, most the respondents are in favour that every institution should be facilitated with internet. In addition, the results of the fourth statement shows that $75 \%$ of the teachers responded in agree and $89 \%$ students' respondents are in the favour of agreed option. It means that most of the respondents are agreed that teacher of mathematics should have ability to use technology to uplift mathematics of the students. Furthermore, the results of the fifth statement shows that $93 \%$ of the teachers agree and 64\% students responded in agree that teachers can make mathematics more understandable through computers. Additionally, the results of the sixth statement shows that about $88 \%$ of the teachers are agree and more than $76 \%$ students are agree that students of mathematics can get latest subject knowledge by using internet. It means that majority of the teachers are agree that internet is useful to get fresh subject knowledge. Also, the results of the seventh statement show that more than $98 \%$ of the teachers are agreed and more than $82 \%$ students responded in agree that ICT reduces manual work. In the same way, the results of the eighth statement show that about $84 \%$ of the teachers are in the favour of agreed option and more than $76 \%$ student respondents are in the favour of 
agreed. That means most of the respondents are agreed that teacher of mathematics should visit relevant websites of keep his/her knowledge fresh. In the same pattern, the results of the ninth statement show that about $92 \%$ of the teachers are in the favour of agreed option and more than $81 \%$ student respondents are in the favour of agreed. It means majority of the respondents are agreed that concepts of mathematics are the base of modern technology. As well as the results of the tenth statement shows that more than $84 \%$ of the teachers are in the favour of agreed option, more than $79 \%$ student respondents are in the favour of agreed. It resulted that most of the respondents are option with the use of computer. Similarly, the results of the above statement shows that more than $78 \%$ of the teachers are in the favour of agreed option, more than $75 \%$ student respondents are in the favour of agreed. Most of the respondents of both categories are agreed that students pay more attention while using computers. In the contradiction to above statements, the results of the above statement shows that less than $39 \%$ of the teachers are in the favour of agreed option, while more than $40 \%$ student respondents are in the favour of agreed option. It means that respondents do not agree that ICT is nothing but a source of entertainment.

\section{Discussion}

In Pakistan educational institutions are under provincial government and due to having a developing country majority of the institutions of secondary level have no facility of any kind of IT laboratories. But since 2010 government of the Punjab (Pakistan) is equipping all the institutions with this technology and giving training to the teachers. According to the new standards for teachers (Ministry of Education, 2010), teachers are required skill in using computers even the teachers of primary level. A computer is now a simple form of IT that is performing a lot of functions for its users even from writing to computing. In its' usage for teaching/learning purposes it saves time and solve complex problems in short period of time. Because now a day a learner has to learn a lot of things in a short period of time, so this kind of technology has become an inevitable thing for the students. But everything has its abuses as well as its usage and in the case of computer and internet that are resourceful for learning mathematics especially and overall education has the same case. So, the students must be guided its usage in a proper way and not to waste time by using it frequently.

\section{Conclusions}

This study addressed the usage of IT in teaching/learning mathematics at secondary level and students and teachers' views about its usage in the class were collected. On the base of findings certain conclusions are made. Mathematics and information technology are closely interlinked, and IT provides valuable information for teachers in the subject of mathematics. So, every institution should be wellequipped with IT laboratory for the promotion of mathematics. Teachers of mathematics should know the usage of IT and for this purpose proper training by the department should be managed. The use of IT is also helpful to motivate to learn so is beneficial for teaching mathematics in class that is said to be a bore subject. It also saves time by computing large amounts in short period of time.

\section{Suggestions}

1. In the institutions teachers should be competent in using technologies that are applicable for teaching/learning purpose (e.g calculator, computer, internet, etc).

2. Institutions should be well equipped with modern IT laboratories and should be in access of every student as well as teachers.

3. Different subjects need different skills of technology so; teachers should properly guide student proper usage of IT and in a proper way and keeping in view about the subject.

4. Improper use of IT either internet waste time and money so teachers and parents should keep eye and guide the students to use it at the time of need. 


\section{References}

National Research Council. (2000). 7 Effective Teaching: Examples in History, Mathematics, and Science. How People Learn: Brain, Mind, Experience, and School: Expanded Edition. Washington, DC: The National Academies Press. doi: 10.17226/9853.

Abramovich, S., Grinshpan, A. Z., Milligan, D. L. (2019). Teaching Mathematics through Concept Motivation and Action Learning. Education Research International, vol. 2019. https://doi.org/10.1155/2019/3745406

Sidhu, K. (1988) The Teaching of Mathematics (3rd Ed.). New Delhi: Sterling Publishers.

Yeo. M. T. (2008). Investigating design and technology students' participation and learning in a technology mediated learning environment. Australasian Journal of Educational Technology. 24(5), 540-555

Oldknow, A. \& Taylor, R. (2002). Teaching Mathematics with ICT (1st Ed.) London: British Library Publications.

Cantürk-Günhan,\& Bukova-Güzel. (2010). Integrating Technology into Mathematics Education: A Case Study from Primary Mathematics Students. Teachers International Journal of Behavioral, Cognitive, Educational and Psychological Sciences. 2(2).

Smeets, E. (2005). Does ICT contribute to powerful learning environments in primary education? Computers \& Education: 44 (2005), 343-355

Regina. M. \& Mistretta. (2005). Integrating Technology into The Mathematics Classroom: The Role of Teacher Preparation Programs. The Mathematics Educator 15(1), 18-24.

Goose, M. and Bennison, A. (2007). Technology-Enriched Teaching of Secondary Mathematics: Factors Influencing Innovative Practice. Mathematics: Essential Research, Essential Practice. 2007(1)

Hartsell, T., Herron, S., Fang, H., \& Rathod, A. (2009). Effectiveness of Professional Development in Teaching Mathematics and Technology Applications. Journal of Educational Technology Development and Exchange. 2(1), 53-64.

Grabe, H., \& Grabe, C. (2000). Integrating the Internet for Meaningful Learning. Boston: Houghton Miffin Company.

Razak, N. A., \& Embi, M. A. (2004). A Framework of IT Competency for English Language Teachers. Internet Journal of e-Language Learning \& Teaching. 1(1), 1-14.

Kumar, S., (1993). Teaching of Mathematics (1st Ed.). New Delhi: Anmol Publications.

O’Neil, Anne-Marie, Clark, J., \& Openshaw, R. (2004). Reshaping Culture, Knowledge and Learning? News land: Dunmore Press Ltd.

Kiliç-Çakmak, E. (2010). Learning strategies and motivational factors predicting information literacy self-efficacy of e-learners. Australasian Journal of Educational Technology. 26(2), 192-208.

UNESCO. (2018). ICT competency for teachers. UK. http://www.unesco.org

Ministry of Education. (2010) Teachers' standards for accreditation. Pakistan: Curriculum Wing. 